\title{
Gas Condensate Wells Simulation to Optimize Well Flow Performance Using Tubing Equations Coupled with Inflow-Performance-Relation (IPR) Curve
}

\author{
Ahmadreza Ejraei Bakyani1 ${ }^{*}$, Alireza Rasti², Sajjad Qazvini ${ }^{3}$, Feridun Esmaeilzadeh4 \\ ${ }^{1}$ Department of Petroleum Engineering, School of Chemical, Petroleum, and Gas Engineering, Shiraz University, Shiraz, Iran \\ ${ }^{2}$ Petropars Operation \& Management Company, Shiraz, Iran \\ ${ }^{3}$ Department of Petroleum Engineering, Marvdasht Branch, Islamic Azad University, Marvdasht, Iran \\ ${ }^{4}$ Professor of the Department of Chemical and Petroleum Engineering, School of Chemical and Petroleum Engineering, Enhanced \\ Oil and Gas Recovery Institute, Advanced Research Group for Gas Condensate Recovery, Shiraz University, Shiraz, Iran \\ Email: *ahmadrezaejraei@gmail.com
}

How to cite this paper: Ejraei Bakyani, A., Rasti, A., Qazvini, S. and Esmaeilzadeh, F. (2018) Gas Condensate Wells Simulation to Optimize Well Flow Performance Using Tubing Equations Coupled with Inflow-Performance-Relation (IPR) Curve. Open Access Library Journal, 5: e4590. https://doi.org/10.4236/oalib.1104590

Received: April 9, 2018

Accepted: May 28, 2018

Published: May 31, 2018

Copyright $\odot 2018$ by authors and Open Access Library Inc.

This work is licensed under the Creative Commons Attribution International License (CC BY 4.0).

http://creativecommons.org/licenses/by/4.0/

\begin{abstract}
Wells performance is evaluated by IPR curves that show the relationship between bottomhole pressure and inflow rate. This curve and its outcome equation can be applied for production schedule and maintenance management of well and reservoir. But, the measuring of bottomhole pressure to approach these curves needs much time and high expenses and also running special tools in wells. In these operations, the probability of catastrophic failure such as well damage or well complete lost may exist. However, these difficulties in offshore wells like production platform in the South Pars gas field that are installed tens kilometers far from lands are harder than any places. Therefore, nowadays by considering these difficulties, there is a high tendency for using wellhead test data that are very inexpensive as well as these data are less accurate than in well data. Moreover, pressure drop due to the existence of gas condensate in well fluid causes the flow regime to be more complicated. Wide researches have been applied to two-phase flow pressure drop in the wellbore and a lot of equations are considered. Anyhow, these equations and their accuracy should be studied in each special case. In this study that is on the south Pars gas condensate field wells, widespread of equations are utilized for calculation of pressure drop in the tubing and they are applied for tubing performance curve as well. In the south pars field wells, the well data of bottomhole pressure are not being measured during production. In this paper, we try to calculate bottomhole pressure by using PIPESIM software and simulating re-
\end{abstract}


servoir fluid and wellbore. For calculating this pressure, with the combination of effective conditions, the best equation of flow regime in that well will be selected. Eventually, by simulation of the reservoir fluid, different parameters like in well performance and proper tubing size is calculated.

\section{Subject Areas}

Chemical Engineering \& Technology, Mechanical Engineering, Mineral

Engineering, Software Engineering

\section{Keywords}

Bottomhole Pressure, Inflow Rate, IPR Curve, Wellhead Data, Gas

Condensate Well

\section{Introduction}

Well performance equations are written based on the well bottomhole pressure and flow rate, but measured bottomhole pressure required time, cost and great equipment. This graph is applied to estimate the well production and production planning for the wells and reservoir management. The main challenge to obtain this graph or inflow performance relation (IPR) is well bottomhole pressure measurement which deals with some main problems.

Pressure drop due to the gas condensate in wells causes complexity of the gas condensate wells flow.

Extensive research on two-phase flow pressure drop in the well column is done and some equations are proposed in this case. However, these equations and their accuracy must be checked for any special case. The study is done on the wells of South Pars gas condensate field. A wide variety of these equations that applied in calculating the pressure drop in the tubing is applied to obtain tubing performance curve.

One of the important parameters in the design of multiphase flow pipeline is determining the number of phases in the system while the process of transmission and distribution, respectively. To investigate and describe multiphase fluid phase behavior, we need to accurately understand and recognize hydrocarbon's phase diagrams (multi-component systems). So that the incorrect results of predicting multiphase fluid phase behavior cause the unacceptable design of the transfer system, separation system, and other multiphase flow operation.

Normally, when a mixture of oil and gas in a flow pipeline, due to lower density and viscosity of the gas phase than the liquid phase, the gas phase will navigate more quickly. In two-phase flow due to retardation or slow-moving liquid phase to the gas phase is called slippage [1]. Research carried out by Orikiszewski [2] showed that the following factors are effective on the large slippage between the phases of two-phase flows inside the pipelines: 1) resistance or irreversible energy loss from friction against the flow direction of the gas phase to 
the liquid phase is much lower, and this makes higher gas phase transfer to the liquid phase in the two-phase flow, even in the absence of strong buoyancy forces, 2) the difference between the density of gas and liquid phases causes the gas phase expands and move at higher speeds and slips on liquid phase. This condition occurs when the pressure of the fluid reduces in the flow direction, 3) slip between liquid and gas phases by the difference in buoyancy forces acting on the phases is promoted in a way that in a resident intermediate liquid, the lighter phase tends to rise at a speed proportional to the phase density difference. Research carried out by Lage and Time [3] showed that most of the theories and relations in two-phase flow were based on the slippage consideration, but some of these relations were based on and taking into account the hypothesis of no slip between phases (homogeneous flow model) have been developed.

Some quantities at the two-phase flow due to the difference in speed between the two phases may have retardation which is a point function. In general, retardation of liquid is called hold up which defined as the ratio of the volume occupied by the fluid (including the volume of liquid and gas) to the total tube volume.

Consultants for expression of physical properties of a fluid based on pure components, the compositional fluid model is applied. So the separation of fluid phase equilibria and homogeneous properties by blending properties of its components, are determined. The accuracy of this model depends on the accuracy in determining the properties of pure components constituting the fluid.

The most important characteristic of two-phase flows is the interface between the gas and liquid phases with the common different shapes. There is the possibility of the existence of an infinite range of different interfaces between two phases. But generally, the effect of surface tension between two phases leads to the creation of curved interfaces that ultimately all of them are into spherical shapes (such as drops and bubbles). There are several flow regime or flow pattern in vertical, horizontal or inclined flow such as bubble or slug flow.

Many relations were applied to predict two-phase flow pressure drop in flow lines in the last decades. The only correct way to predict empirical evaluation of the two-phase pressure drop is compared the predicted pressure drop with measurement or practical pressure drop (in fields). Evaluation of empirical equations of pressure drop was conducted by several researchers. All of these comparative studies are generally preferred method proposed by researchers.

A group of researchers including Brill-Lawson and Vohra et al., examined nine empirical relations using field data from 726 wells follows as below: 1-Poettmann, Carpenter [4], 2-Baxendell, Thomas [6], 3-Duns, Ros [7], 4-Fancher, Brown [11], 5-Hagedorn, Brown [8], 6-Orkiszewski [2], 7-Beggs, Brill [12], 8-Aziz et al. [13], 9-Chierici et al. (1974).

It should be noted that all these researchers have applied the same empirical relations to predict and calculate phase properties in all these methods. For comparison the results of this study, the parameters of the mean deviation $(A P D)$ and standard deviation $(S D)$ are applied as follows: 


$$
\begin{gathered}
A P D=\sum_{i=1}^{n} e_{i} / n \\
S D=\left[\sum_{i=1}^{n}\left(e_{i}-A P D\right)^{2} / n-1\right]^{0.5}
\end{gathered}
$$

In the above relations, " $n$ " is the total number of data related to pressure drop and deviation, " $e_{i}$ ” can be determined by the following equation:

$$
e=100\left(\frac{\Delta P_{1}-\Delta P_{2}}{\Delta P_{1}}\right)
$$

Table 1 demonstrates the result of the deviation of the methods.

According to Table 1, it is observed that all these methods with the exception of Aziz et al. [13], led to the prediction of excessive amounts of pressure, and the only Hagedorn-Brow method [8], gives more acceptable results than other methods.

For gas condensate reservoirs usually, the Duns and Ros [7], Gray, Ansari, and Govier Aziz Fogorasi relations are applied. The relations Govier Aziz Fogorasi is the first relation to study the pressure drop in gas condensate production wells which has been developed. The Gary relation (Shell Company) for vertical flow of gas and condensate with the higher gas volume than condensate system is developed to. Gray relation is limited to less than 3.5 inch diameter pipe and condensate ratio less than $50 \mathrm{bbl} / \mathrm{mmscf}$. Also in the modified Gray relation, Reynolds number and the roughness of the pipe was corrected. Hasan and Kabir by using the West Africa field data and field data collected by Govier Fogorasi investigated the Aziz et al., Gray, and Ansari relations and non-slippage flow and finally calculated bottomhole pressure with the help of wellhead pressure. Hasan and Kabir proposed that Gray relation and analytical Ansari model during foggy conditions tend to homogeneous model and bottomhole pressure can be obtained from both models with the lower error.

One of the applications of well performance modeling is related to well's cement performance as Carey et al. [23] work that Analysis and performance of oil

Table 1. Deviations results of predicted correlations for pressure drop calculations (Lawson Brill 1974).

\begin{tabular}{ccc}
\hline Method & Mean deviation percent & Standard deviation \\
\hline Poettmann, Carpenter & -107.3 & 195.7 \\
Baxendell, Thomas & -108.3 & 195.1 \\
Fancher, Brown & -5.5 & 36.1 \\
Duns, Ros & -15.4 & 50.2 \\
Hagedorn, Brown & -1.3 & 26.1 \\
Orkiszewski & -8.6 & 35.7 \\
Beggs, Brill & -17.8 & 27.6 \\
Aziz et al. & +8.2 & 34.7 \\
Chierici et al. & +42.8 & 43.9 \\
\hline
\end{tabular}


well cement with 30 years of $\mathrm{CO}_{2}$ exposure from the SACROC Unit, West Texas, USA was obtained. Related to hydraulic fractured wells, Fan and Thompson [24] after integration of all available data, they built the stimulated well's simulation models with multistage hydraulic fracture treatments. This model investigates parameters relating to well performance including 1) pore pressure, 2) matrix rock quality, 3) natural fractures, 4) hydraulic fractures, and 5) complex fracture networks. By history-matching of observed production, the primary factors for creating good early well performance were identified. Also, Miller, Jenkins, and Rai [25] modeled a new production technique to obtain fracture characterization, reservoir properties, and well performance in shale gas reservoirs. Recently, Ghahri et al. [26] have developed a new and simple model to simulate the horizontal wells productivity. They have considered the phase change around the horizontal wells which causes the relative permeabilities of the both condensate and gas phases. Therefore, they can simulate the fluid flow as well as the productivity around the horizontal wells, and they have developed an in-house simulator to numerically simulate the productivity of the horizontal wells, as well. Also, Hekmatzadeh and Gerami [27] have presented a new and fast analytical approach to predict the production profile in the gas condensate wells. They have applied the material balance and pseudo-pressure integral equations to develop the desired approach. Their analytical approach is able to exactly predict the plateau time as well as the high-velocity flow near the wellbore phenomena in the gas condensate wells. Totally, flow equations through the wellbore as well as the tubing construct the inflow and tubing models of the gas condensate wells productivity. However, many researchers have studied on the surface models of the gas condensate reservoirs such as chock model or separator model. Ejraei Bakyani et al. [28] have proposed a simple simulator to thermodynamically design a separator model in the gas condensate reservoirs.

In this paper, the best tubing equation compatible with the empirical data has been chosen as the Tubing-Performance-Relation (TPR). Also, the Rawlins and Schellhardt inflow equation compatible with the empirical data has been chosen as the IPR. By applying the sensitivity analysis on the most effective parameters, the best coupled IPR-TPR model has been proposed as a semi-empirical model to optimize the flow equation through the gas condensate wells.

\section{Methodology}

This simulation steps are carried out as follows. Figure 1 shows the flowchart.

1) Getting the required data for the simulator run.

2) Plot pressure gradient through the well based on the different pressure gradient relations.

3) Plot pressure gradient through the well based on the measured pressure gradient data obtained from the PSP.

4) Compare the pressure gradient curves obtained from steps 2 and 3.

5) Select a best or accurate relation has the best fit on PSP data as the optimum 


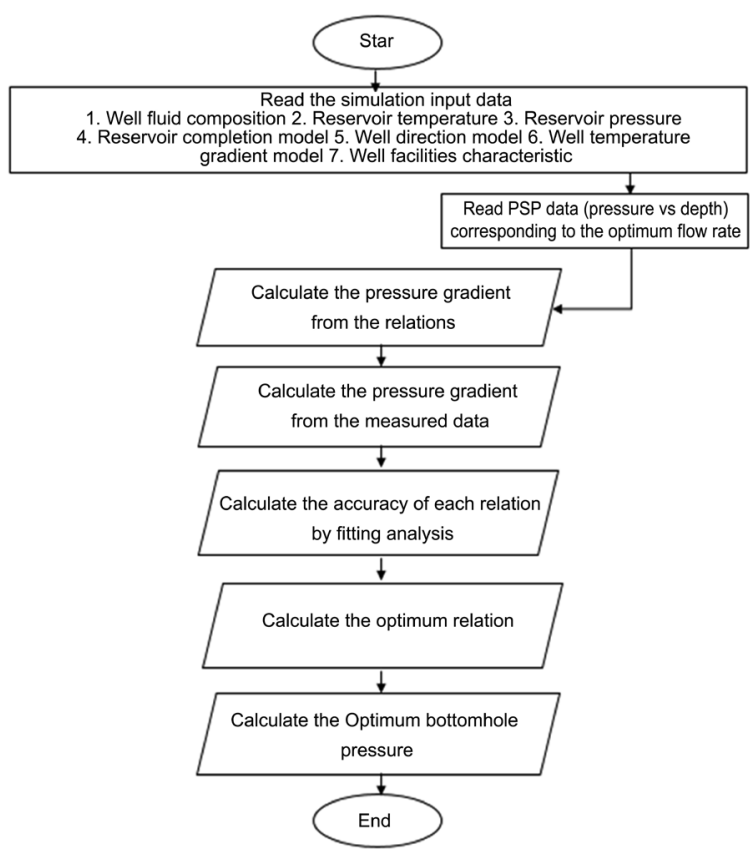

Figure 1. Simulation flowchart.

pressure gradient relation.

6) Calculate the bottomhole pressure from the selective optimum pressure gradient relation.

7) Calculate the well head pressure from the corresponding calculated bottomhole pressure.

8) Plot the IPR and Tubing-Performance-Relation (TPR) curves and obtain the required parameters including optimum production rate.

9) Change some parameters in order to see their impact on bottomhole pressure.

Table 2 demonstrates the pressure gradient relations used in the simulation.

Simulation of reservoir fluids properties is usually the most accurate method for analysis of reservoir fluids characteristic, especially in the wet gas systems, condensate, and volatile oil. So, in any case to accurate whether information about reservoir fluids is low available for production engineers, equation of state is the best choice. The ideal gas low is accurate for gas systems in low pressure and or high temperature. But for some gas systems, such as gas condensate reservoirs with high pressure and temperature, it is so inaccurate. As a result, more accurate equations of state of gases and condensate have been developed. The equations that are applied in the simulation study are Viscosing equation of state, multi flash, and sis flash. Sis flash test includes two and three parameter Peng-Robinson (PR) equation of state. Multi flash test also includes PR, BWRS, SRK, standard PR, and standard SRK. In this paper we utilize the multi flash equations of state, PR equation of state, which are more flexible than other groups. Also, in viscosity calculation by two LBC and Pedersen method, Pedersen method is used because of lower sensitivity to used equation of state than LBC 
Table 2. Pressure gradient relations applied in the simulation.

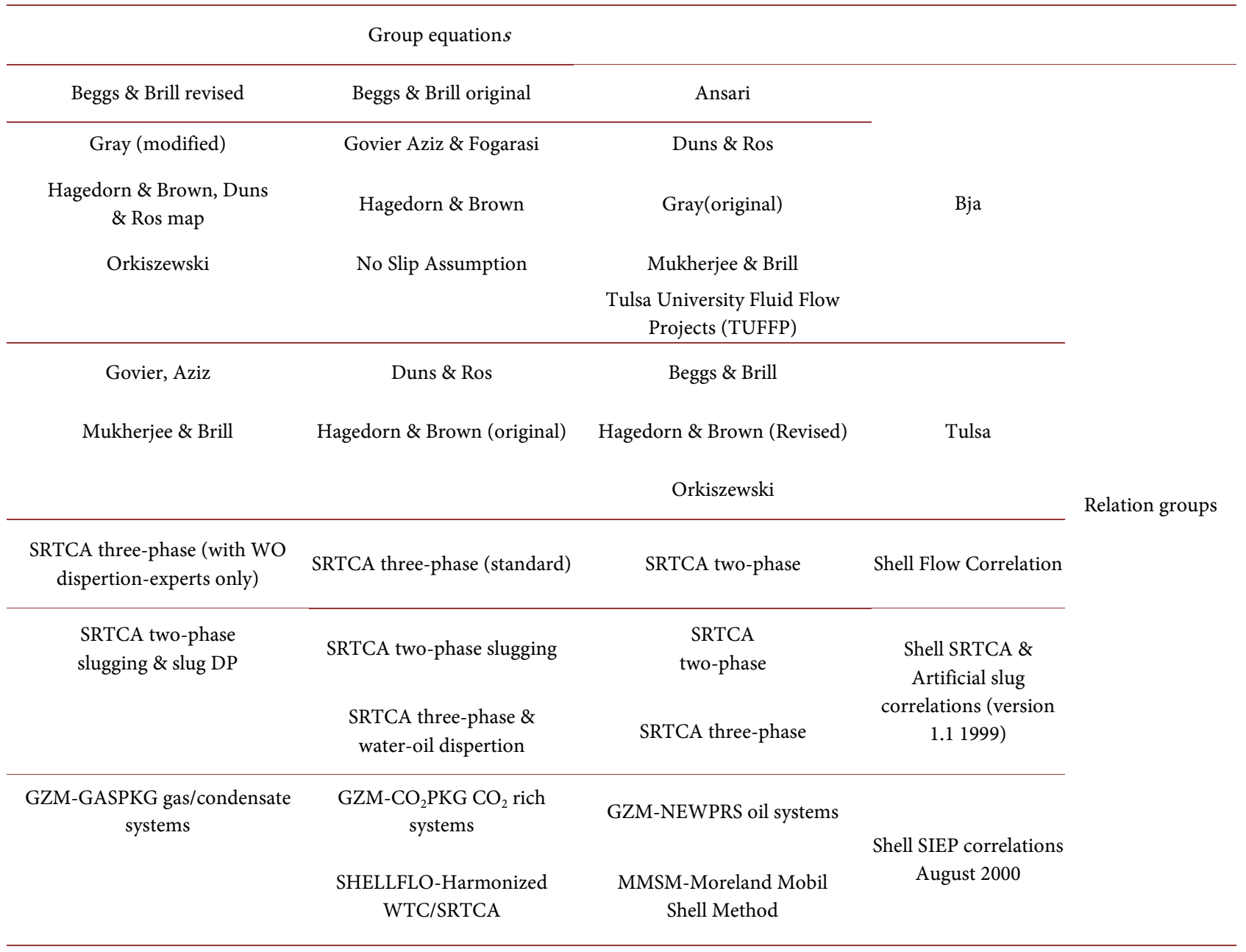

method. In $55 \%$ - 70\%water production is called the cutoff point. The emulsion viscosity is calculated by volume ratio method.

Based on flow data analysis for a large number of gas wells have been obtained from Rawlins and Schellhardt (1936), a relationship between gas flow rate $\left(Q_{S C}\right)$ and squared pressure drop, reservoir pressure $\left(P_{R}\right)$ and well flow pressure $\left(P_{w f}\right)$, that can be expressed as follows: [29]

$$
Q_{S C}=C\left(P_{R}^{2}-P_{w f}^{2}\right)^{n}
$$

The variable " $n$ " represents the excessive fluid pressure drop due to high gas velocity or turbulence effect and may range from 1 to laminar flow and to 0.5 for turbulent flow and variable " $C$ " in the above equation related to reservoir rock properties, reservoir fluid properties, and reservoir geometry.

In gas condensate reservoirs, the annular-mist flow regime is more common. In this paper the Turner drops model is applied for the simulation of condensate drops flow around and within the well. Within the well, gas velocity causes a drag force acting on the drops. If drag force resulted by gas velocity is equal to gravity force of drop, gas velocity is called critical gas velocity. In velocity lower 
than critical velocity, drops fall and we can see liquid loading phenomenon in the wellbore, and in velocity higher than critical velocity, drops rise. Figure 2 shows the Turner drop model of the simulation [30] [31].

\section{Results and Discussion}

The information needed to build a simulation model in the software environment should be investigated.

The measured depths of facilities in the simulated well N1 are considered as 309.67, 2061, and 2725 for SSSV, tubing, and liner, respectively.

Table 3 demonstrates PSP data obtained practically related to the simulated well N1.

For simulation, PVT properties of the reservoir fluids which are showed in Table 4 are tuned by PVTi software. Gravity of the reservoir fluid is 40.36 API.

Finally, relations in the software is used to calculate pressure drop with the help of main required input data for the well pressure drop simulation as Table 4.

\subsection{Select the Optimum Relation}

At first Figure 3 shows the plots of the different pressure gradient relations as well as the measured data pressure gradient in three flow rates which are reported in PSP data and the corresponding wellhead pressures.

According to the above figures, it is obvious that Hagedorn \& Brown (original) relation has the best fit or the lower error (Table 5).

\subsection{Optimum Relation Sensitivity Analysis}

Varying the friction factor and the holdup factor parameters are to reduce the error of the Hagedorn \& Brown (original) pressure gradient relation that this relation is not sensitive to these two parameters. Table 6 demonstrates the the results of the sensitivity analysis.

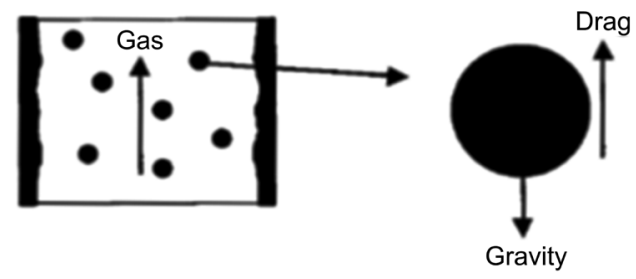

Figure 2. Turner drop model scheme.

Table 3. PSP data related to the simulated well N1.

\begin{tabular}{ccccc}
\hline Depth $(\mathrm{m})$ & Q (MMSCFD) & Pwh (Psia) & Twh (F) & Pwf (Psia) \\
\hline 2725 & 82 & 3440 & 181.04 & 4378 \\
2725 & 57 & 3525 & 179.96 & 4424 \\
2725 & 33 & 3624 & 139.46 & 4488 \\
\hline
\end{tabular}


Table 4. Required input data for the well pressure drop simulation.

\begin{tabular}{|c|c|c|c|c|}
\hline Well Fluid Composition & Comp. & Mole \% & $\begin{array}{l}\text { Molecular } \\
\text { Weight }\end{array}$ & $\begin{array}{l}\text { Specific } \\
\text { Weight }\end{array}$ \\
\hline & $\mathrm{H}_{2} \mathrm{~S}$ & 0.2 & 34.076 & \\
\hline & $\mathrm{CO}_{2}$ & 2.2 & 44.01 & \\
\hline & $\mathrm{N}_{2}$ & 3.0 & 28.013 & \\
\hline & $\mathrm{C}_{1}$ & 78.9 & 16.043 & \\
\hline & $\mathrm{C}_{2}$ & 7.2 & 30.07 & \\
\hline & $\mathrm{C}_{3}$ & 3.4 & 44.097 & \\
\hline & $\mathrm{IC}_{4}$ & 0.1 & 58.124 & \\
\hline & $\mathrm{NC}_{4}$ & 0.4 & 58.124 & \\
\hline & $\mathrm{IC}_{5}$ & 0.318 & 72.151 & \\
\hline & $\mathrm{NC}_{5}$ & 0.8882 & 72.151 & \\
\hline & $\mathrm{C}_{6}$ & 0.5975 & 84 & 0.685 \\
\hline & $\mathrm{FR}_{1}$ & 1.3471 & 107.34 & 0.73937 \\
\hline & $\mathrm{FR}_{2}$ & 0.8904 & 146.11 & 0.78182 \\
\hline & $\mathrm{FR}_{3}$ & 0.5588 & 222.47 & 0.8431 \\
\hline Reservoir Pressure- $\mathrm{P}_{\mathrm{r}}(\mathrm{Psia})$ & \multicolumn{4}{|c|}{4555.39} \\
\hline Reservoir Temperature- $T_{r}(F)$ & \multicolumn{4}{|c|}{215} \\
\hline Well Performance Model or Reservoir Model & \multicolumn{4}{|c|}{ Fetkovitch } \\
\hline Well Completion Model & \multicolumn{4}{|c|}{ Cased-hole } \\
\hline Well Direction Model (m) & & \multicolumn{2}{|c|}{$\begin{array}{c}\text { No Inclination } \\
\text { Vertical Well }\end{array}$} & \\
\hline Temperature Gradient Model & \multicolumn{4}{|c|}{ Hagedorn \& Brown (original) } \\
\hline Bottomhole Facilities Model & \multicolumn{4}{|c|}{ Packer, Production Casing, Tubing, ... } \\
\hline Pressure Drop Calculation Optimum Model & \multicolumn{4}{|c|}{ Plot Pressure vs. Depth } \\
\hline
\end{tabular}

Table 5. Errors of Hagedorn \& Brown (original) pressure gradient relation based on the measured data pressure gradient.

\begin{tabular}{cccccc}
\hline $\begin{array}{c}\text { Well } \\
\text { Number }\end{array}$ & $\begin{array}{c}\text { WHP from } \\
\text { PSP (Psia) }\end{array}$ & $\begin{array}{c}\text { WHP from } \\
\text { Correlation (Psia) }\end{array}$ & $\begin{array}{c}\text { Gas Rate } \\
\text { (MMSCFD) }\end{array}$ & Math Correlation & Er \% \\
\hline$\# 1$ & 3440 & 3443.6 & 82 & Hagedorn \& Brown (original) & 0.1 \\
$\# 1$ & 3525 & 3570.8 & 57 & Hagedorn \& Brown (original) & 1.3 \\
$\# 1$ & 3624 & 3663.7 & 33 & Hagedorn \& Brown (original) & 1.1 \\
\hline
\end{tabular}

Table 6. Results of the sensitivity analysis of the friction factor and the holdup factor on the optimum relation.

\begin{tabular}{ccccc}
\hline Math Correlation & Q (MMSCFD) Friction Factor Hold up Factor & $\begin{array}{c}\text { WHP from } \\
\text { Pipesim (Psia) }\end{array}$ \\
\hline Hagedorn \& Brown (original) & 82 & 1.5 & 1 & 3443.6 \\
Hagedorn \& Brown (original) & 82 & 1 & 1.5 & 3443.6 \\
Hagedorn \& Brown (original) & 82 & 1.5 & 1.5 & 3443.6 \\
\hline
\end{tabular}




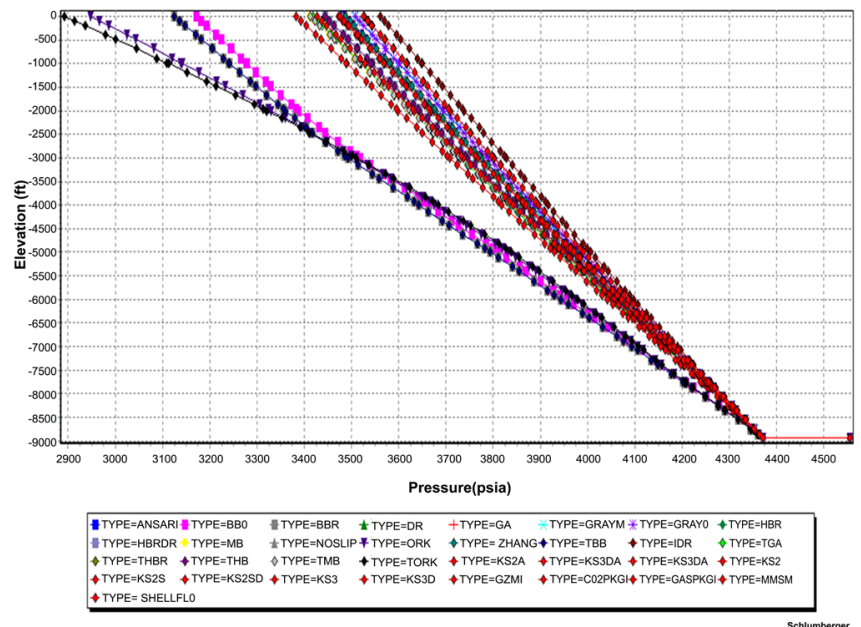

(a)

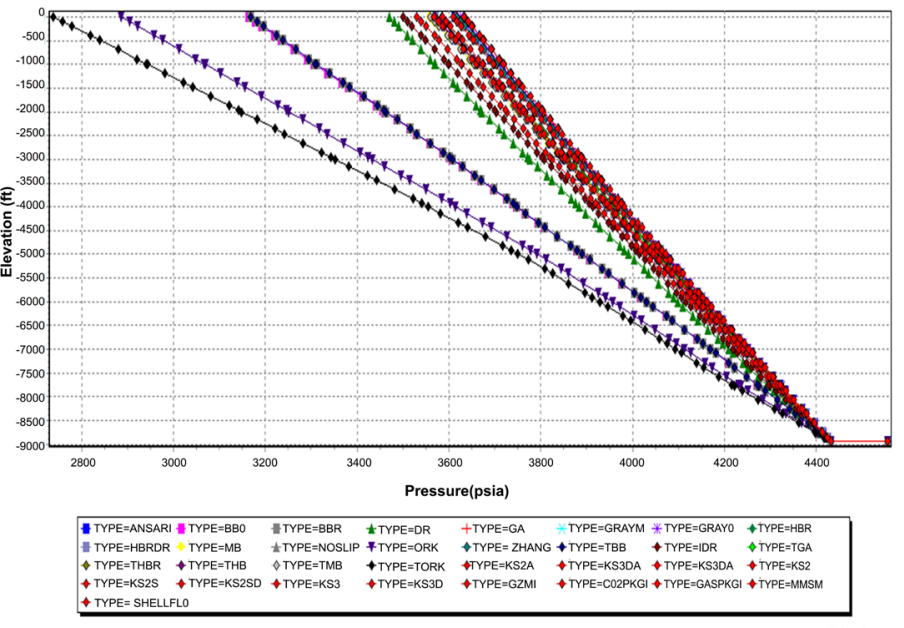

(b)

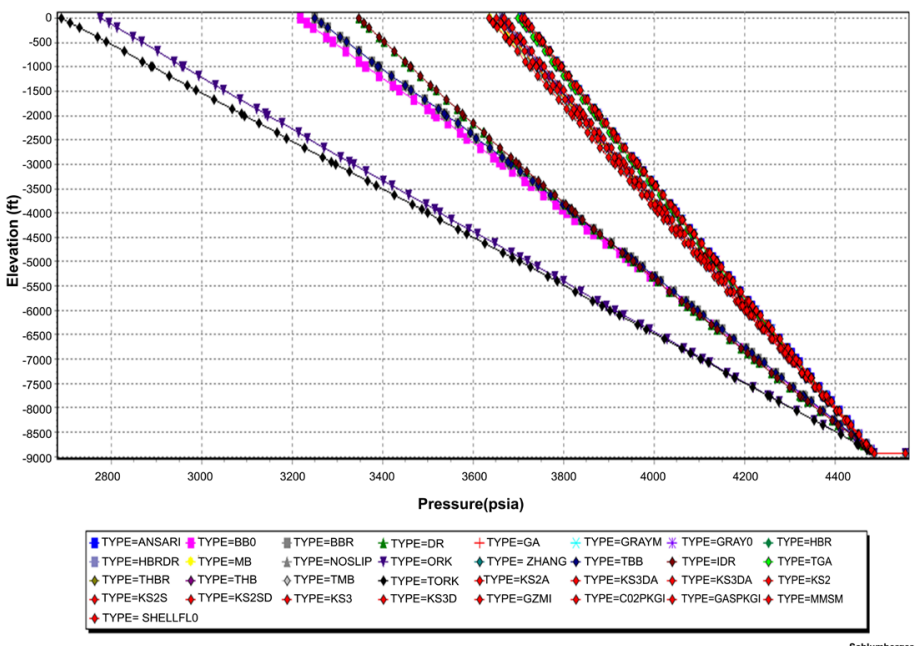

(c)

Figure 3. Different pressure gradient relations vs. measured data pressure gradient at (a) 82 MMSCFD rate and 3440 Psia wellhead pressure; (b) 57 MMSCFD rate and 3525 Psia wellhead pressure; and (c) 33 MMSCFD rate and 3624 Psia wellhead pressure. 


\subsection{Optimum Relation Temperature Gradient}

Figure 4 shows the plots of Hagedorn \& Brown (original) temperature profile in three flow rates. Table 7 demonstrates the errors of Hagedorn\& Brown (original) temperature profilebased on the calculated wellhead temperature.

\subsection{Possibility of Two-Phase Flow Formation in the Well Column by the Optimum Relation}

Figure 5 shows PVT phase diagram of the model applied in this simulation. Figure 6 shows the magnified area identified in Figure 5 to study the formation of two-phase flow. Three flow rates 33, 57, and 82 MMSCFD are selected as well. Accordingly, the reservoir static pressure is above the dew point curve, but the flowing bottomhole pressure for flow rates 57 and 82 MMSCFD is under the dew point curve, showing the formation of two-phase flow in the well column. Also, two-phase flow is formed for flow rate 33 MMSCFD at a depth of 2682 meters.

\subsection{Calculate the Optimum Bottomhole Pressure}

After the choice of the optimum relation, the optimum bottomhole pressure is calculated with the help of Hagedorn \& Brown (Original) and Gray (modified) pressure gradient relations. At first, Figure 7 shows the credible data chosen by investigating the available wellhead pressure and flow rate.

Now bottomhole pressure can be calculated by Hagedorn \& Brown (Original) pressure gradient relation at the various wellhead pressures and flow rates.

Finally, with the help of the calculated bottomhole pressure and according to the log-log plot " $\left(P_{\mathrm{ws}}{ }^{2}-P_{\mathrm{wf}}{ }^{2}\right)$ vs. Q", the parameters n (-), and c (MMSCFD/Psi $\left.{ }^{2}\right)$ can be predicted as 0.73395466 and 0.0025888781 , respectively. Also, the flow turbulency can be investigated.

\subsection{Sensitivity Analysis}

The wellhead pressure as well as the flow rate is applied as input data. Table 8 demonstrates the sensitivity analysis on the flow rate by $5 \%$ variation. Therefore, the sensitivity analysis is done and Figure 8(a) shows that the flow rate variation has a low effect on the bottomhole pressure.

Also, Table 8 demonstrates the sensitivity analysis applied on the wellhead pressure by $5 \%$ variation. Therefore, the sensitivity analysis is done and Figure 8 (b) shows that the wellhead pressure variation has a considerable

Table 7. Errors of Hagedorn \& Brown (original) temperature profile based on the calculated wellhead temperature.

\begin{tabular}{ccccc}
\hline Math Correlation & $\begin{array}{c}\text { Gas Rate } \\
\text { (MMSCFD) }\end{array}$ & WHT (F) & $\begin{array}{c}\text { WHT from } \\
\text { Pipesim (F) }\end{array}$ & Er \% \\
\hline Hagedorn \& Brown (original) & 82 & 181 & 201.7 & 11.44 \\
Hagedorn \& Brown (original) & 57 & 180 & 200.3 & 11.27 \\
Hagedorn \& Brown (original) & 33 & 176 & 196.5 & 11.64 \\
\hline
\end{tabular}




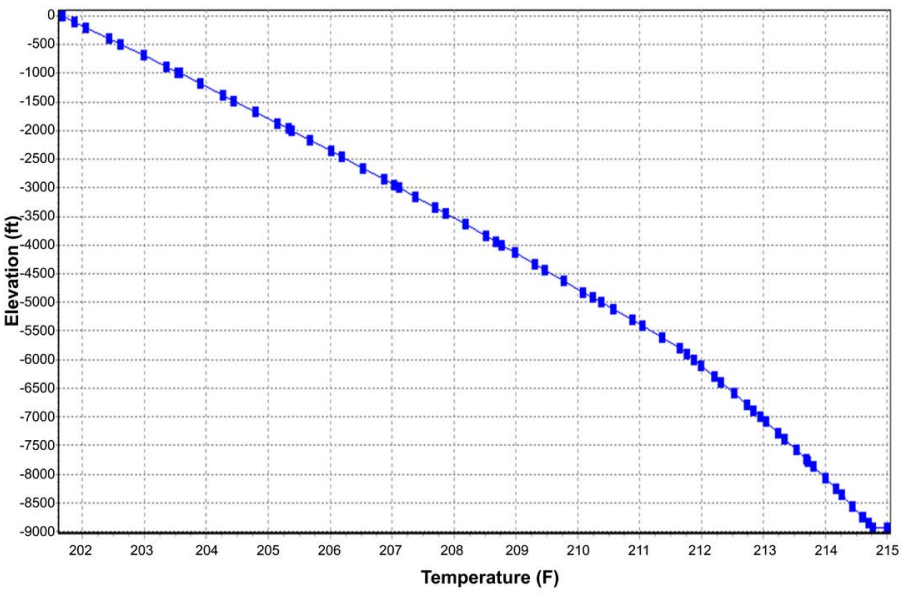

ISeries0

(a)

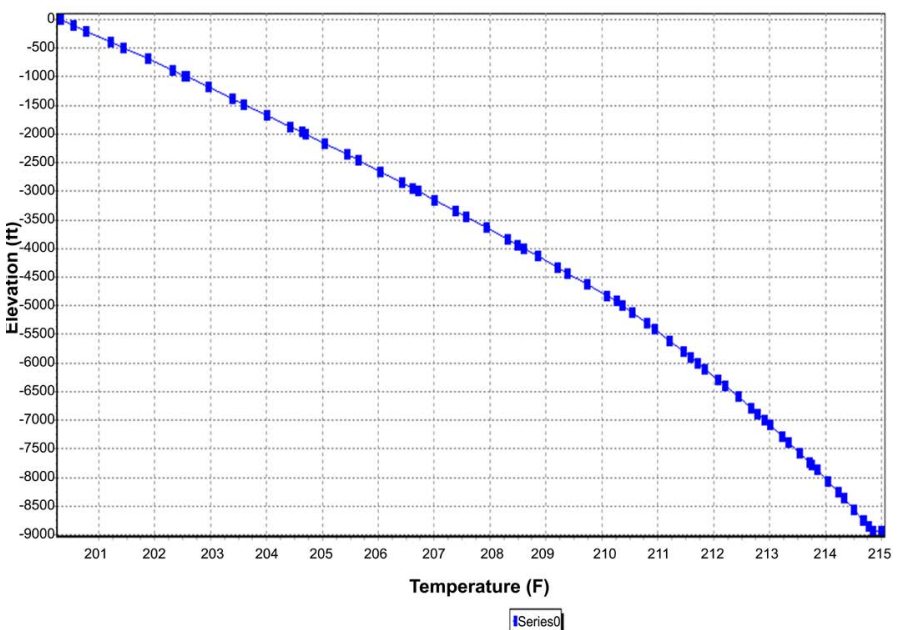

(b)

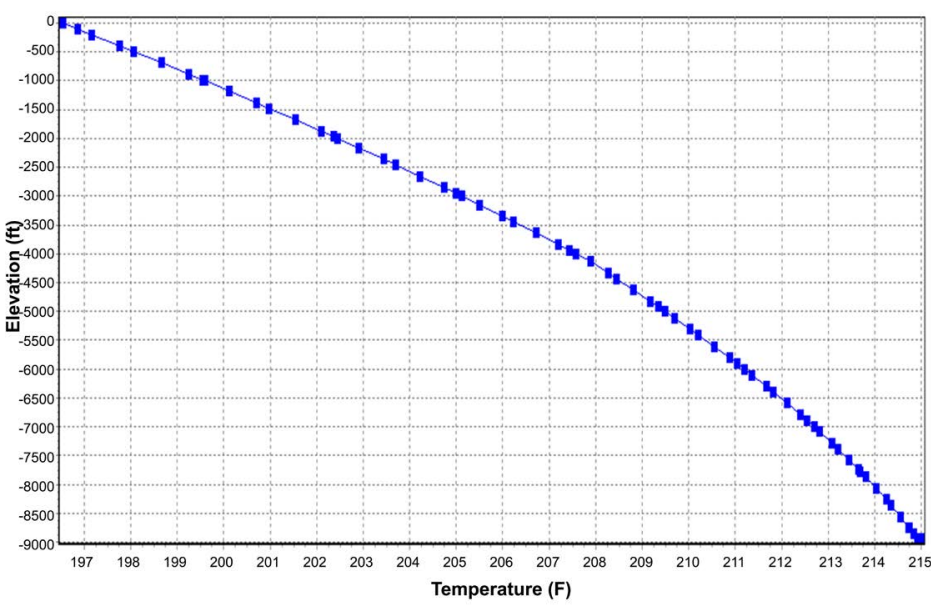

ISeries0

(c)

Figure 4. Hagedorn\& Brown (original)temperature profile at (a) 82 MSCFD; (b) 57 MSCFD; and (c) 33 MSCFD. 


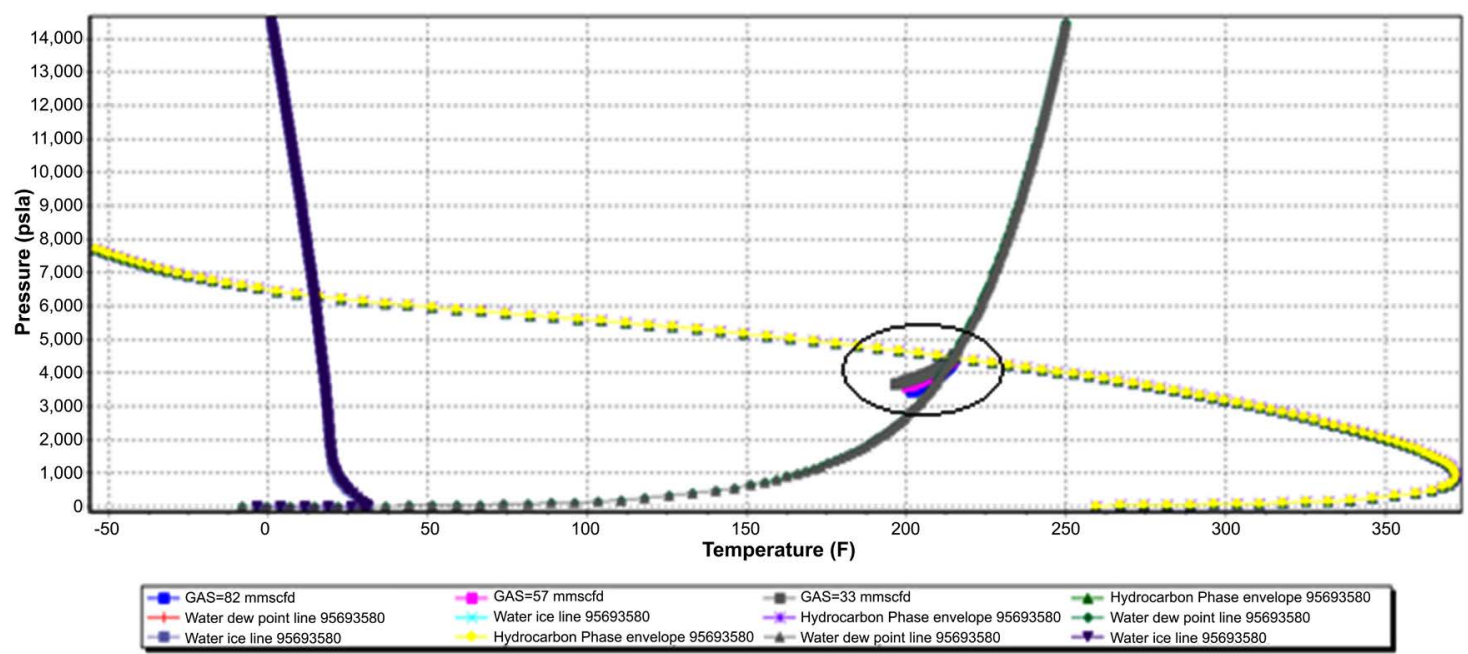

Figure 5. PVT phase diagram of the model applied in the simulation.

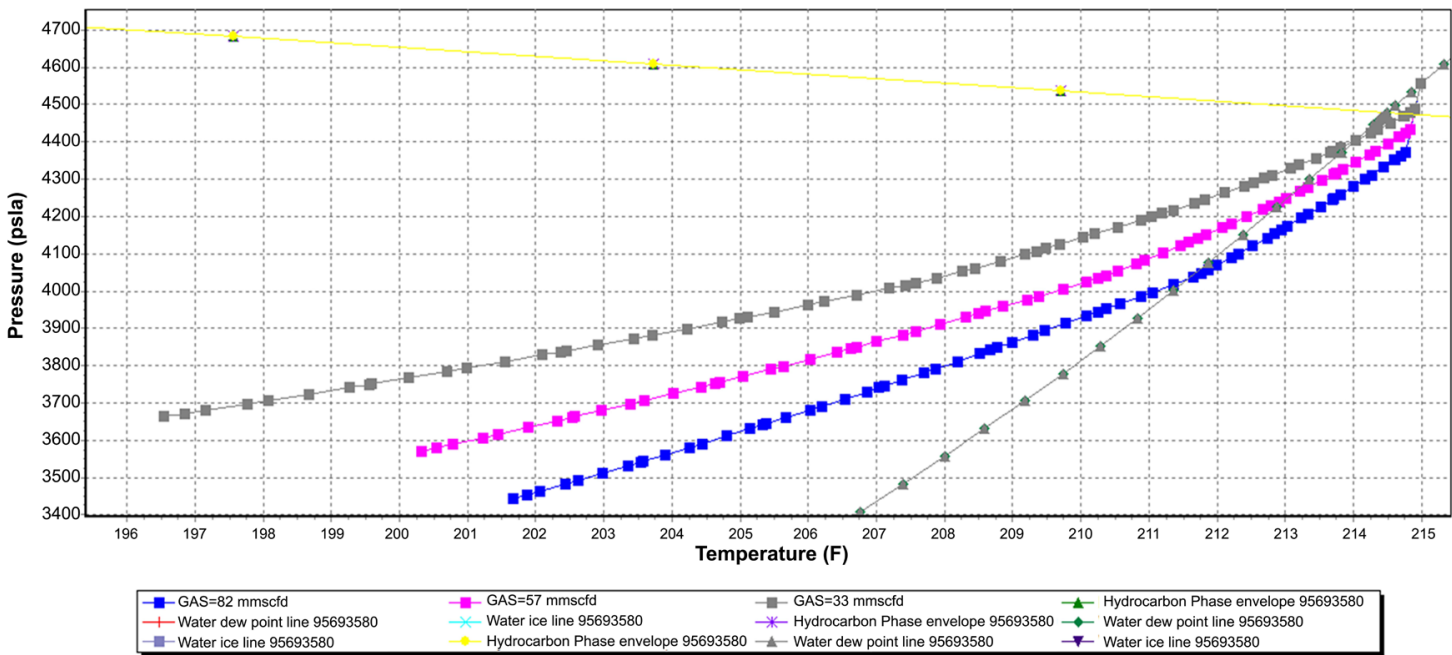

Figure 6. Investigation of two-phase flow formation in the well column at flow rate 33, 57, and 82 MMSCFD.

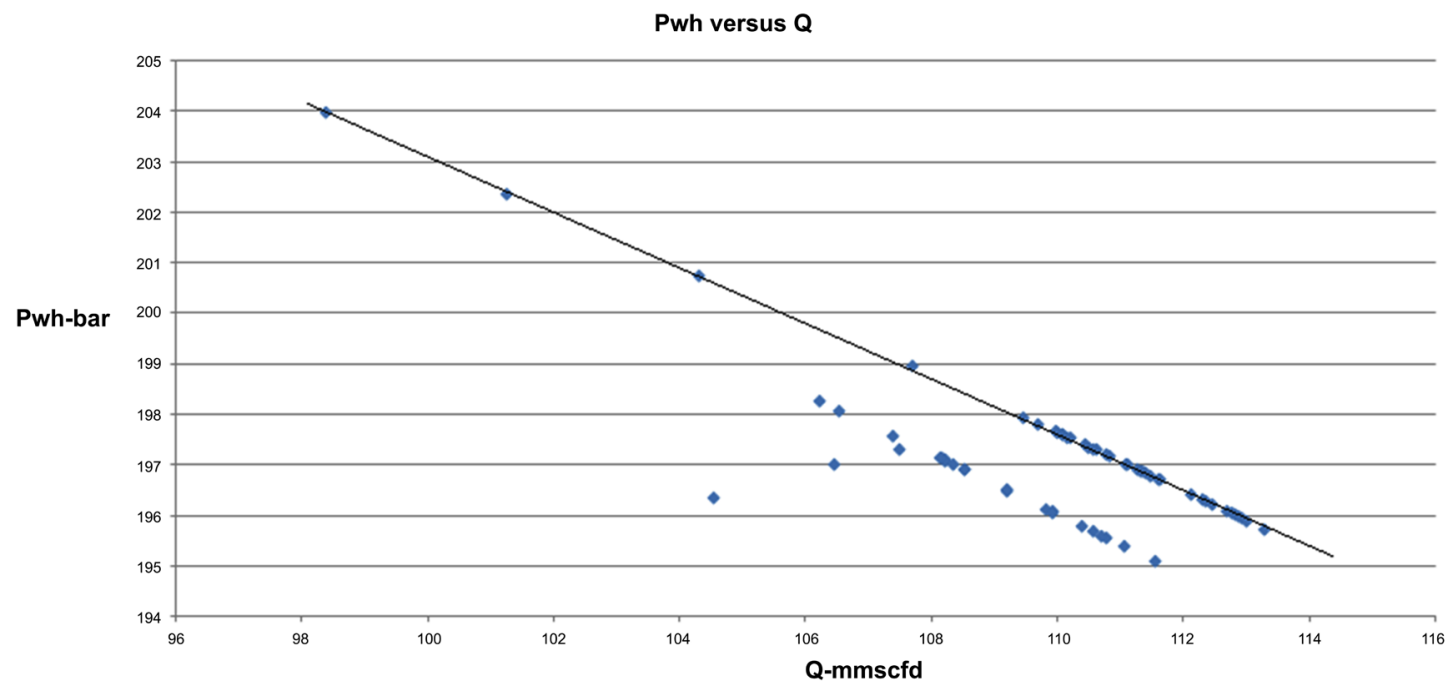

Figure 7. Investigation of the creditability of the wellhead pressure and the flow rate data. 


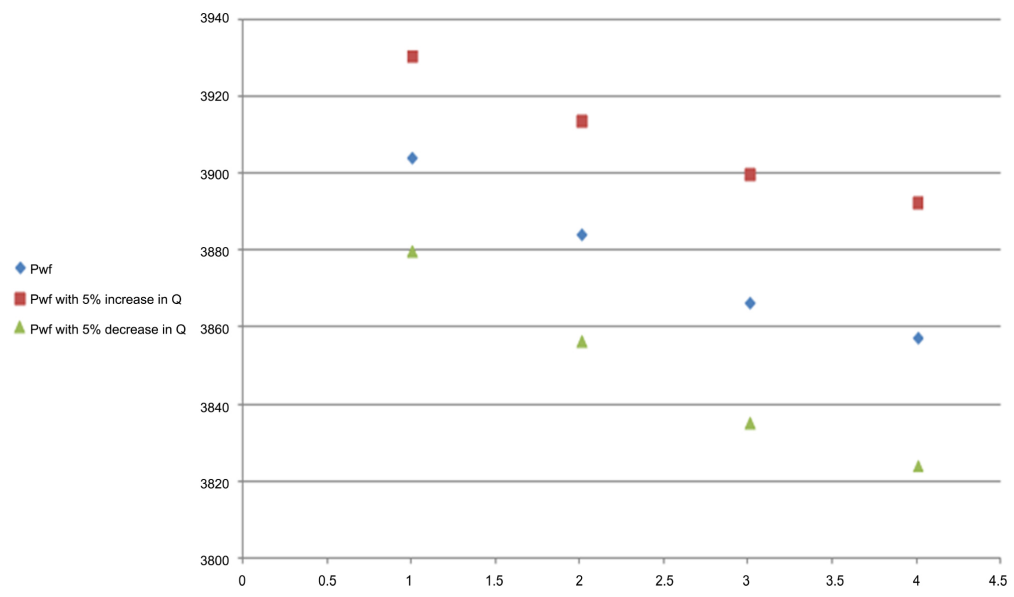

(a)

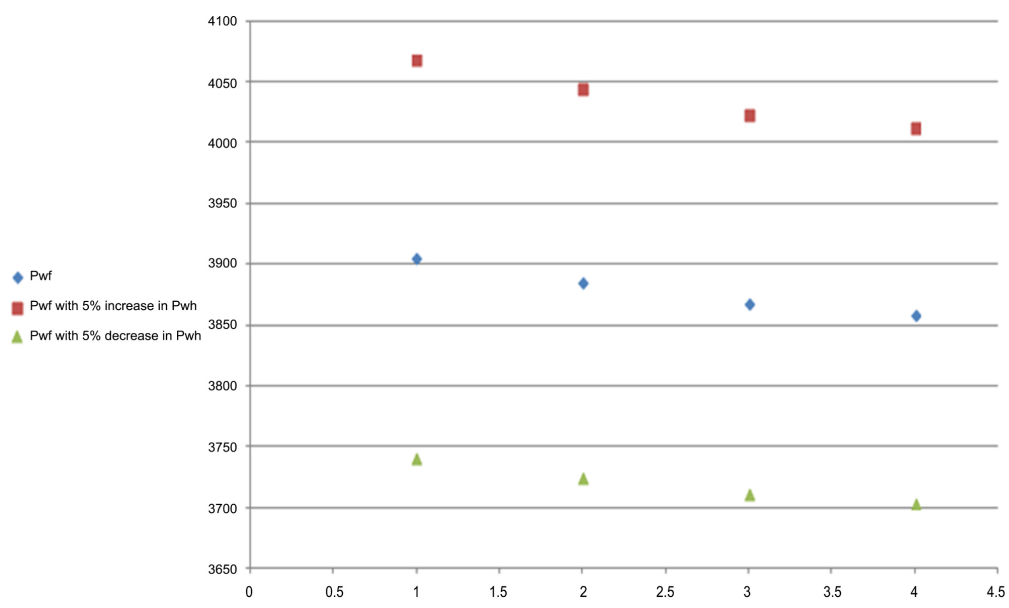

(b)

Figure 8. Bottomhole pressure variation by doing a sensitivity analysis on the (a) flow rate and (b) wellhead pressure.

Table 8 . Sensitivity analysis by $5 \%$ variation of the flow rate and the wellhead pressure.

\begin{tabular}{ccc}
\hline Q (MMSCFD) with $+5 \%$ & Pwh (Psia) & Pwf (Psia) \\
\hline 103.28 & 2958.5 & 3930.4 \\
109.48 & 2912.1 & 3913.9 \\
115.55 & 2866.2 & 3900 \\
118.62 & 2841.6 & 3892.5 \\
Q (MMSCFD) with $-5 \%$ & Pwh (Psia) & Pwf (Psia) \\
93.44 & 2958.5 & 3879.7 \\
99.06 & 2912.1 & 3856.5 \\
104.55 & 2866.2 & 3835.5 \\
107.32 & 2841.6 & 3824.2 \\
Q (MMSCFD) & Pwh (Psia) with $+5 \%$ & Pwf (Psia) \\
98.36 & 3106.425 & 4068.5 \\
104.27 & 3057.705 & 4045.1 \\
110.05 & 3009.51 & 4023.9 \\
112.97 & 2983.68 & 4012.4 \\
\hline
\end{tabular}


Continued

\begin{tabular}{ccc}
\hline Q (MMSCFD) & Pwh (Psia) with $-5 \%$ & Pwf (Psia) \\
98.36 & 2810.575 & 3740.1 \\
104.27 & 2766.495 & 3724.3 \\
110.05 & 2722.89 & 3710.9 \\
112.97 & 2699.52 & 3703.7 \\
\hline
\end{tabular}

effect on the bottomhole pressure. Moreover, by increasing the wellhead pressure, the calculated bottomhole pressure increases.

\section{Conclusions}

The Hagedorn \& Brown (original) pressure gradient relation has the best fit or the lower error in prediction of bottomhole pressure in this gas condensate well study. Therefore, this relation can be applied in other cases with close characteristic and can be replaced with the high time and cost operation. Also, this relation at the higher flow rate has an accurate results in the pressure gradient prediction.

Hagedorn \& Brown (original) pressure gradient relation at every flow rate is not sensitive to the friction factor and the holdup factor parameters. Therefore, in any quantities of these parameters or any effects, causing an increase or decrease, doesn't effect on this relation ability to predict the bottomhole pressure.

Hagedorn \& Brown (original) pressure gradient relation can be applied to predict the wellhead temperatur. However, at 57 MMSCFD flow rate, the predicted wellhead temperature is more accurate.

Two-phase flow in the gas condensate well can be formed in the well column at a higher flow rate. At a lower flow rate two-phase flow in the gas condensate well can be formed in the well column at a higher depth. In this case, two-phase flow can be formed for 33 MMSCFD flow rate at 2682 meters.

The bottomhole pressure can be easily and low-costly obtained by this relation with a high accuracy, because of the elimination data points which at these points the wellhead pressure and the flow rate data sets are not valuable.

The well performance curve can be plotted and " $n$ " and " $c$ " parameters are obtained. " $n$ " quantity shows an intermediate laminar-turbulent well flow in this case. Also, the calculated " $n$ " parameter that is between 0.5 and 1 is a reason for acceptable analysis by this method.

The sensitivity analysis is done and shows that the flow rate variation has a low effect on the bottomhole pressure with the at acceptable results at any flow rate.

The sensitivity analysis is done and shows that the wellhead pressure variation has a considerable effect on the bottomhole pressure. Additionally, by increasing the wellhead pressure, the calculated bottomhole pressure increases.

Finally, this relation shows so good results as mentioned previously. So, this is usable to construct TPR and IPR curves and obtain the optimum flow rate in this case. 


\section{Acknowledgements}

The authors are grateful to the south Pars gas Company for supporting this research's data.

\section{References}

[1] Hasan, A.R. and Kabir, C.S. (1992) Two-Phase Flow in Vertical and Inclined Annuli. International Journal of Multiphase Flow, 18, 279-293. https://doi.org/10.1016/0301-9322(92)90089-Y

[2] Orkiszewski, J. (1967) Predicting Two-Phase Pressure Drops in Vertical Pipe. Journal of Petroleum Technology, 19, 829-838. https://doi.org/10.2118/1546-PA

[3] Lage, A.C. and Time, R.W. (2000) Mechanistic Model for Upward Two-Phase Flow in Annuli. SPE Annual Technical Conference and Exhibition, Dallas, 1-4 October 2000, Document ID: SPE-63127-MS. https://doi.org/10.2118/63127-MS

[4] Poettman, F.H. and Carpenter, P.G. (1952) The Multiphase Flow of Gas, Oil, and Water through Vertical Flow Strings with Application to the Design of Gas-Lift Installations. Drilling and Production Practice, New York, 1 January 1952, Document ID: API-52-257.

[5] Ros, N.C.J. (1961) Simultaneous Flow of Gas and Liquid as Encountered in Well Tubing. Journal of Petroleum Technology, 13, Document ID: SPE-18-PA. https://doi.org/10.2118/18-PA

[6] Baxendell, P.B. and Thomas, R. (1961) The Calculation of Pressure Gradients in High-Rate Flowing Wells. Journal of Petroleum Technology, 13, Document ID: SPE-2-PA. https://doi.org/10.2118/2-PA

[7] Duns Jr., H. and Ros, N.C.J. (1963) Vertical Flow of Gas and Liquid Mixtures in Wells. 6th World Petroleum Congress, Frankfurt, 19-26 June 1963, Document ID: WPC-10132.

[8] Hagedorn, A.R. and Brown, K.E. (1965) Experimental Study of Pressure Gradients Occurring during Continuous Two-Phase Flow in Small-Diameter Vertical Conduits. Journal of Petroleum Technology, 17, 475-484. https://doi.org/10.2118/940-PA

[9] Hunt, D., Lie, J.T., Vohra, J. and Sloman, G. (1973) Histopathology of Heart Block Complicating Acute Myocardial Infarction. Circulation, 48, 1252-1261. https://doi.org/10.1161/01.CIR.48.6.1252

[10] Vohra, I.R., Robinson, J.R. and Brill, J.P. (1974) Evaluation of Three New Methods for Predicting Pressure Losses in Vertical Oil Well Tubing. Journal of Petroleum Technology, 26, 829-832. https://doi.org/10.2118/4689-PA

[11] Fancher Jr., G.H. and Brown, K.E. (1963) Prediction of Pressure Gradients for Multiphase Flow in Tubing. Society of Petroleum Engineers Journal, 3, 59-69. https://doi.org/10.2118/440-PA

[12] Beggs, D.H. and Brill, J.P. (1973) A Study of Two-Phase Flow in Inclined Pipes. Journal of Petroleum Technology, 25, 607-617. https://doi.org/10.2118/4007-PA

[13] Aziz, K. and Govier, G.W. (1972) Pressure Drop in Wells Producing Oil and Gas. Journal of Canadian Petroleum Technology, 11, Document ID: PETSOC-72-03-04. https://doi.org/10.2118/72-03-04

[14] Gray, H.E. (1978) Vertical Flow Correlation in Gas Wells. User's Manual for API 14B Surface Controlled Subsurface Safety Valve Sizing Computer Program. 2nd Edition, American Petroleum Institute, Dallas. 
[15] Oyewole, A. (2015) Extension of the Gray Correlation to Inclination Angles. SPE Annual Technical Conference and Exhibition, Houston, 28-30 September 2015, Document ID: SPE-178727-STU. https://doi.org/10.2118/178727-STU

[16] Ansari, A.M., Sylvester, N.D., Sarica, C., Shoham, O. and Brill, J.P. (1994). A Comprehensive Mechanistic Model for Upward Two-Phase Flow in Wellbores. SPE Production \& Facilities, 9, 143-151. https://doi.org/10.2118/20630-PA

[17] Shirdel, M. and Sepehrnoori, K. (2012) Development of a Transient Mechanistic Two-Phase Flow Model for Wellbores. Society of Petroleum Engineers Journal, 17, 942-955. https://doi.org/10.2118/142224-PA

[18] Govier, G.W. and Fogarasi, M. (1975) Pressure Drop in Wells Producing Gas and Condensate. Journal of Canadian Petroleum Technology, 14, Document ID: PETSOC-75-04-03. https://doi.org/10.2118/75-04-03

[19] Ebrahimi, A. and Khamehchi, E. (2015) A Robust Model for Computing Pressure Drop in Vertical Multiphase Flow. Journal of Natural Gas Science and Engineering, 26, 1306-1316. https://doi.org/10.1016/j.jngse.2015.08.036

[20] Kabir, C.S. and Hasan, A.R. (2004) Simplified Wellbore Flow Modeling in Gas-Condensate Systems. SPE Annual Technical Conference and Exhibition, Houston, 26-29 September 2004, Document ID: SPE-89754-MS.

https://doi.org/10.2118/89754-MS

[21] Kabir, C.S. and Hasan, A.R. (2006) Simplified Wellbore Flow Modeling in Gas-Condensate Systems. SPE Production \& Operations, 21, 89-97.

https://doi.org/10.2118/89754-PA

[22] Fuad, I.I.M., Lee, J.H., Akhir, N.A.M. and Zulkifli, I. (2017) Enumeration Approach in Condensate Banking Study of Gas Condensate Reservoir. SPE Abu Dhabi International Petroleum Exhibition \& Conference, Abu Dhabi, 13-16 November 2017, Document ID: SPE-188589-MS. https://doi.org/10.2118/188589-MS

[23] Carey, J.W., Wigand, M., Chipera, S.J., WoldeGabriel, G., Pawar, R., Lichtner, P.C. and Guthrie, G.D. (2007) Analysis and Performance of Oil Well Cement with 30 Years of $\mathrm{CO}_{2}$ Exposure from the SACROC Unit, West Texas, USA. International Journal of Greenhouse Gas Control, 1, 75-85.

https://doi.org/10.1016/S1750-5836(06)00004-1

[24] Fan, L., Thompson, J.W. and Robinson, J.R. (2010) Understanding Gas Production Mechanism and Effectiveness of Well Stimulation in the Haynesville Shale through Reservoir Simulation. Canadian Unconventional Resources and International Petroleum Conference, Calgary, 19-21 October 2010, Document ID: SPE-136696-MS. https://doi.org/10.2118/136696-MS

[25] Miller, M.A., Jenkins, C.D. and Rai, R.R. (2010) Applying Innovative Production Modeling Techniques to Quantify Fracture Characteristics, Reservoir Properties, and Well Performance in Shale Gas Reservoirs. SPE Eastern Regional Meeting, Morgantown, 13-15 October 2010, Document ID: SPE-139097-MS.

https://doi.org/10.2118/139097-MS

[26] Ghahri, P., Jamiolahmadi, M., Alatefi, E., Wilkinson, D., Dehkordi, F.S. and Hamidi, H. (2018) A New and Simple Model for the Prediction of Horizontal Well Productivity in Gas Condensate Reservoirs. Fuel, 223, 431-450. https://doi.org/10.1016/j.fuel.2018.02.022

[27] Hekmatzadeh, M. and Gerami, S. (2018) A New Fast Approach for Well Production Prediction in Gas-Condensate Reservoirs. Journal of Petroleum Science and Engineering, 160, 47-59. https://doi.org/10.1016/j.petrol.2017.10.032

[28] Bakyani, A.E., Heidari, S., Rasti, A. and Namdarpoor, A. (2018) Development an 
Easy-to-Use Simulator to Thermodynamic Design of Gas Condensate Reservoir's Separators. Modeling and Numerical Simulation of Material Science, 8, Article ID: 82227. https://doi.org/10.4236/mnsms.2018.81001

[29] Amao, A.M. (2007) Mathematical Model for Darcy Forchheimer Flow with Applications to Well Performance Analysis. Ph.D. Thesis, Texas Tech University, Lubbock.

[30] Lea, J.F. and Nickens, H.V. (2004) Solving Gas-Well Liquid-Loading Problems. Journal of Petroleum Technology, 56, 30-36. https://doi.org/10.2118/72092-JPT

[31] Bellarby, J. (2009) Tubing Well Performance, Heat Transfer and Sizing. Developments in Petroleum Science, 56, 247-302.

https://doi.org/10.1016/S0376-7361(08)00205-7 